\title{
Experimental and Simulation Research on the Influence of Stirring Parameters on the Distribution of Particles in Cast SiCp/A356 Composites
}

\author{
Zhiyong Yang, Like Pan, Jianmin Han, Zhiqiang Li, Jialin Wang, Xiang Li, and Weijing Li \\ School of Mechanical, Electronic and Control Engineering, Beijing Jiaotong University, Beijing 100044, China \\ Correspondence should be addressed to Zhiyong Yang; zhyyang@bjtu.edu.cn
}

Received 24 January 2017; Accepted 3 April 2017; Published 19 April 2017

Academic Editor: Qudong Wang

Copyright (C) 2017 Zhiyong Yang et al. This is an open access article distributed under the Creative Commons Attribution License, which permits unrestricted use, distribution, and reproduction in any medium, provided the original work is properly cited.

\begin{abstract}
Achieving the uniform distribution of reinforcement particles in MMCs is very important for the effect of stirring parameters and the flow action of the melt, which should be known. The effect of stirring parameters on the distribution of SiC particles in SiCp/A356 composites was studied by the experimental and numerical methods in this paper. The experimental results show the $\mathrm{SiC}$ distribution with different stirring parameters. In addition, the effects of the fluid velocity and volume fraction of $\mathrm{SiC}$ particle at different position of crucible on the $\mathrm{SiC}$ distribution were analyzed by numerical simulation. The velocity magnitude, axial velocity, and radial velocity were analyzed to explain theoretically the particle distribution. The shearing force, moments, and stirring power of the stirring rod were simulated based on CFD code. The numerical results show that the stirring temperature is lower, the shearing force is greater, the stirring time is longer, and particle dispersion gets better. On the other hand, the higher the stirring speed is, the more uniform the radial and axial flow are, and the better the particles were dispersed. The numerical results were in good agreement with the experimental data.
\end{abstract}

\section{Introduction}

Particle reinforced metal matrix composites (PMMCs) are used in a variety of structural applications ranging from civil transportation to aerospace [1]. Stirring casting has been widely used in the preparation of SiCp/A356 composite materials because of its simplicity, flexibility, and applicability to large quantity production. However, there was one problem that was associated with the production of reinforced composited, primarily the difficulty of achieving a homogeneous distribution of reinforcement in the matrix [2].

A uniform particle distribution is essential in PMMCs, as it can effectively improve the mechanical properties of composite materials and also reduce the porosity and particle clusters in composites, improve the interfacial condition, and reduce the probability of crack formation and expansion. Hashim et al. [3,4] reviewed the stirring parameter causing the porosity and particle clustering, which were phenomena of uneven distribution of particles and harmful to the mechanical properties of the composites. Ahmad et al. [5] studied the effects of porosity on the mechanical properties; Zhang and Li [6] and Su et al. [7] studied the effects of the particle clustering on the mechanical properties.

In recent years, experimental and CFD simulation methods had been used to study the effects of stirring parameters on the particle distribution in PMMCs. Prabu et al. [8] and ElKaddah and Chang [9] studied the influence of stirring speed and stirring time on particle distribution by experiment. Naher et al. [10], Ghosh and Ray [11], and Ravi et al. [12] studied the effect of stirring speed on uniform distribution of particles by scaled-up visualization experiments simulation. Naher et al. [13] attempted the particle distribution in the glycerol/water system with experimental and CFD simulation. The experiments and simulation had been conducted with similar characteristics of liquid and particle. But the study of $\mathrm{SiC}$ and aluminum characteristics of liquid and semisolid is very little. The process of SiC's involvement in aluminum alloy is very complicated, including the interaction between the particles and the interaction between the particles and the matrix alloy. The change of stirring temperature, 


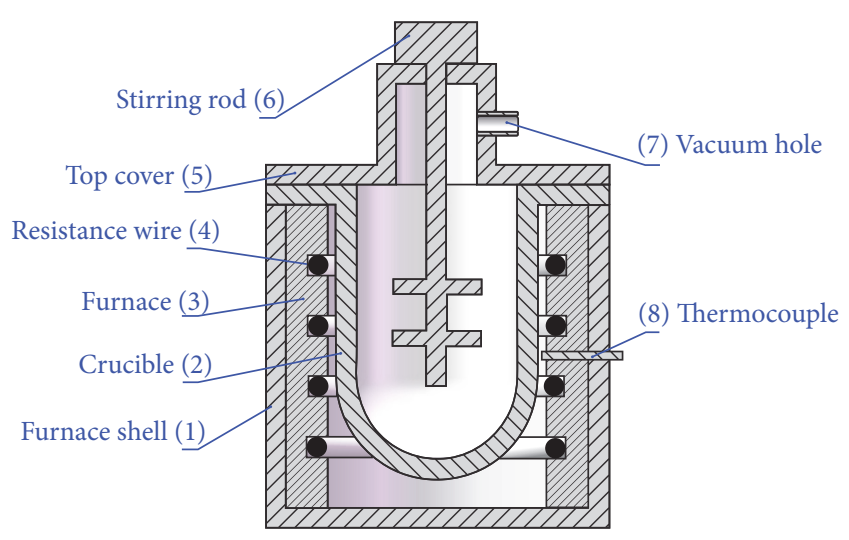

FIgURE 1: The sketch of the experiment equipment.

stirring speed, and stirring time impacted on the distribution of particles. At present, the scholars mainly used the experiment or similar characters of particles and fluid to simulate the distribution of particles. But the force and velocity of particles in the stirring casting process are not clear enough, and the reason of particle distribution is not clearly understood for the $\mathrm{SiCp} / \mathrm{Al}$ composite. Therefore, it is necessary to carry out the experiment at the same time, to further understand the force of particles in the stirring process and to finally know the particles distribution mechanism and the law.

The main objective of this work is to study the effects of stirring parameter on the $\mathrm{SiC}$ distribution in liquid and semisolid PMMCs with vacuum semisolid stirring casting and numerical simulation. And the study of this work reveals the stirring force, the fluid velocity, and volume fraction of $\mathrm{SiC}$ particle under different stirring parameters. The study results will help us to understand the mechanism and law of particle distribution more clearly.

The aluminum alloy and particles constituted a two-phase system in which liquid and solid coexisted at the same time. The particle distribution in such systems could be theoretically found by solving the transport equations for both solid and liquid phases. In this study, the Non-Newtonian fluid was considered to determine particle distribution during the stirring process. The particle distribution was determined by the volume fractions of second phase distribution.

\section{Experimental}

2.1. Apparatus and Materials. Figure 1 shows a sketch of the apparatus to prepare the $\mathrm{SiCp} / \mathrm{A} 356$ composites by stirring casting, which in essence consists of a stainless steel crucible, a stirring rod, and a vacuum hole for vacuum pumping. The stirring speed varied from 100 to $2000 \mathrm{rpm}$.

The commercial casting grade A356 aluminum alloy matrix and $\alpha$-SiC particles with average sizes of $20 \mu \mathrm{m}$ were selected. The chemical composition of the A356 and $\mathrm{SiC}$ is listed in Tables 1 and 2, respectively. The microstructure of the matrix and particles is shown in Figure 2, and the liquid and solid temperature of A356 is $520 \sim 620^{\circ} \mathrm{C}$, respectively.
TABLE 1: The chemical composition of A356.

\begin{tabular}{lccccccc}
\hline Element & $\mathrm{Si}$ & $\mathrm{Mg}$ & $\mathrm{Ti}$ & $\mathrm{Fe}$ & $\mathrm{Cu}$ & $\mathrm{Mn}$ & $\mathrm{Ni}$ \\
\hline Wt.\% & 7.23 & 0.332 & 0.128 & 0.112 & 0.001 & 0.001 & 0.001 \\
\hline
\end{tabular}

TABLE 2: The chemical composition of SiC.

\begin{tabular}{lccccc}
\hline Element & $\mathrm{SiC}$ & $\mathrm{C}$ & $\mathrm{Si}$ & $\mathrm{SiO}_{2}$ & $\mathrm{Fe}_{2} \mathrm{O}_{3}$ \\
\hline Wt.\% & 97.2 & 0.28 & 0.23 & 1.73 & 0.56 \\
\hline
\end{tabular}

2.2. Experimental Procedures. The A356 aluminum alloy was melted under vacuum environment in resistance furnace. Firstly, Mg element was added and degassed vacuum was conducted by means of stirring; secondly, the pretreated SiC particles were added and the stirring was maintained until the temperature dropped to the semisolid temperature and the particles were fully involved to the aluminum; thirdly, the stirring speed was improved and stirring was kept for minutes. Finally, the melt was heated and poured into the metal mold. The metallographic specimen was grinded and the particle dispersion was observed.

During the experiment process, under the condition of vacuum, the molten metal was well stirred to degasification, and the $\mathrm{SiC}$ particles were involved into the melt. The speed of the stirring rod was ranged from 600 to $1200 \mathrm{rpm}$. The $\mathrm{SiC}$ particles were preheated at $600^{\circ} \mathrm{C}$ for 2 hours and then fed into the semisolid aluminum alloy. The semisolid composite slurry with $\mathrm{SiC}$ was stirred continuously during varying the stirring speed, stirring temperature, and stirring time. The stirring temperature was controlled under 620,600, and $580^{\circ} \mathrm{C}$, and the stirring time was selected at 10,20 , and $30 \mathrm{~min}$ after the addition of $\mathrm{SiC}$. The $\mathrm{SiC}$ volume percentage of $\mathrm{SiCp} / \mathrm{A} 356$ composites at different position of the crucible was measured by accounting the $\mathrm{SiC}$ particle of metallographic samples, which were polished and viewed in an optical microscope.

\section{Simulation}

The Eulerian multiphase model of Fluent Version 12.1 was used for the simulation of two-phase flow of aluminum and $\mathrm{SiC}$ in the crucible. The $\mathrm{A} 356$ and $\mathrm{SiC}$ were treated as the primary phase and secondary phase, respectively. The viscosity of aluminum slurry was varied with temperature and stirring speed during the melting and stirring process, and the NonNewtonian power law was used for the viscosity of the different stirring temperature and stirring speed of the aluminum. The standard $k$-epsilon turbulent model was chosen to model the aluminum and $\mathrm{SiC}$ mixing system. The transient change process of fluid was simulated by using Multiple Reference Frame (MRF) and sliding mesh model. The 3D computational model is shown in Figure 3. All of the volume percentages of $\mathrm{SiC}$ measurements reported here were taken along the axial and radial direction, which is shown in Figure 3(b).

The CFD model was divided into three zones, the rotation zone, stationary zone, and $\mathrm{SiC}$ addition zone in the initial time. Before simulation, the $\mathrm{SiC}$ was placed in the $\mathrm{SiC}$ addition zone and the $\mathrm{SiC}$ volume fraction was observed in 


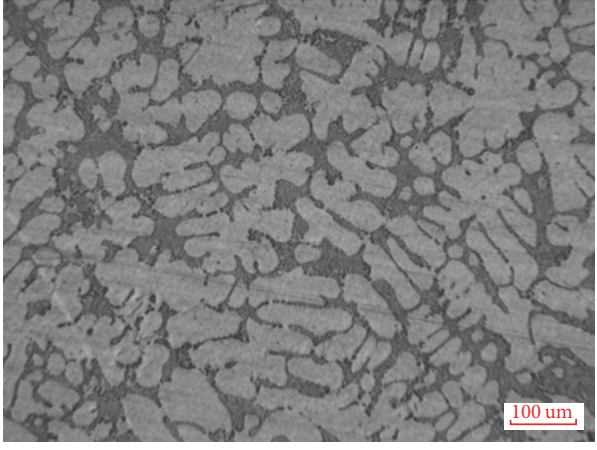

(a)

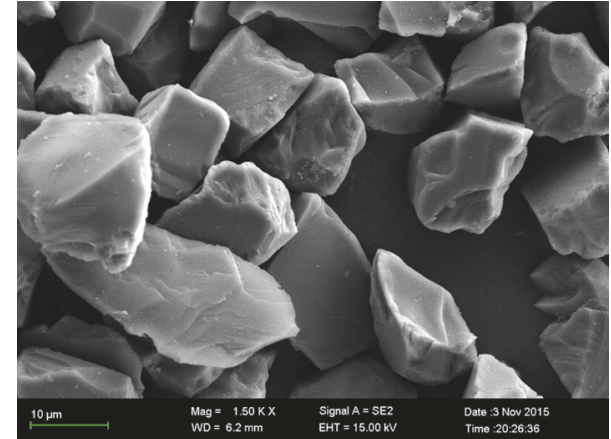

(b)

Figure 2: Microstructure of A356 and SiC particles.

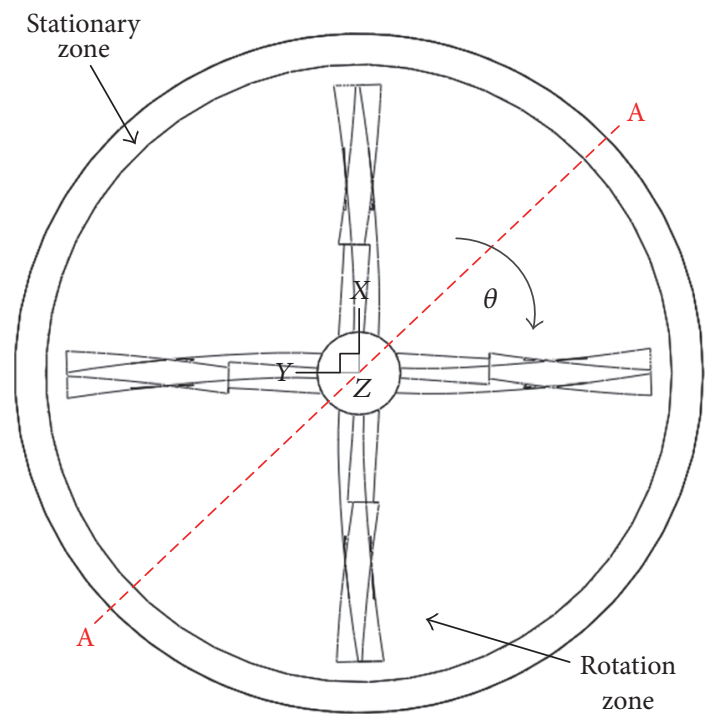

(a)

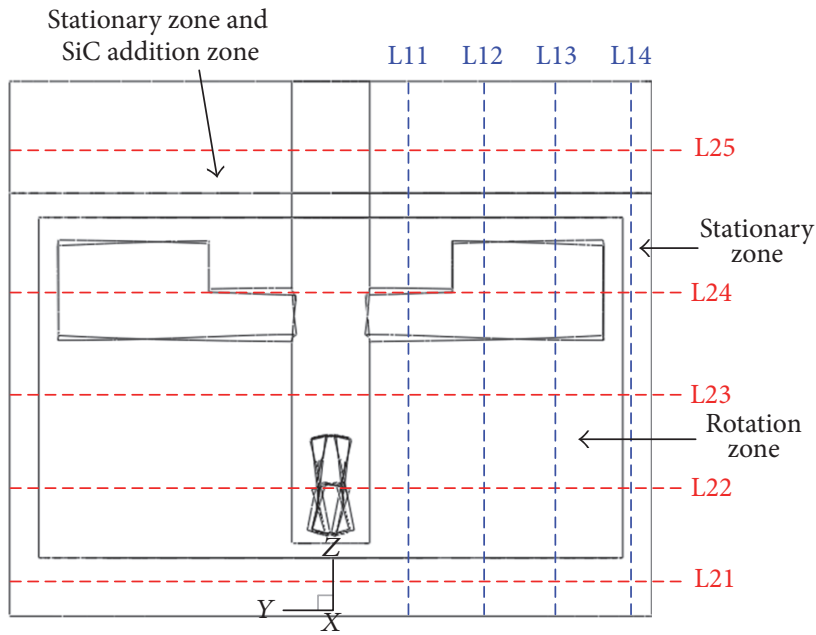

(b)

Figure 3: The CFD model and selected position: (a) the plan view and A-A lines represent the plane to view the volume fraction of SiC; (b) the elevation on A-A. Lines L11 L14 and L21 L25 are positions to view the SiC volume fraction in the computational simulation.

the simulation process. The top wall of crucible was set to symmetry, and the other wall of crucible was set to stationary wall. The stirring rod wall was set to rotation wall, which rotated in the simulation process.

The viscosity of aluminum was important for the simulation, which depended on the temperature, stirring speed, and $\mathrm{SiC}$ volume percentage. The aluminum alloy melt was NonNewtonian fluid. The Non-Newtonian viscosity was chosen for the simulation and modeled according to the following power law for the Non-Newtonian viscosity [14]:

$$
\eta=k \dot{\gamma}^{n^{\prime}-1} H(T),
$$

where $\eta$ is effective viscosity, $k$ and $n^{\prime}$ are input parameters, $\dot{\gamma}$ is average shear rate, $k$ is a measure of the average viscosity of fluid (the consistency index), and $n^{\prime}$ is a measure of the deviation of the fluid from Newtonian (the power law index). The value of $n^{\prime}$ determines the class of the fluid.

Einstein's equation was used to model the viscosity of the PMMC [15]:

$$
\eta_{1}=\eta_{0}\left(1+2.5 f_{s}\right)
$$

where $\eta_{1}, \eta_{0}$ represent the viscosity of aluminum alloy melt with and without adding particles and $f_{s}$ is the volume fraction solid.

Zhang el al. [16] measured the semisolid slurry of A356 aluminum alloy and developed an empirical equation that shows the effect of fraction solid and shearing rate on the viscosity of semisolid A356 alloy:

$$
\eta=2.79 \exp \left(6.27 f_{s}\right) \dot{\gamma}^{-0.7} .
$$

The viscosity of computational simulation fluid was calculated by (1), (2), and (3). The viscosity was varied with 


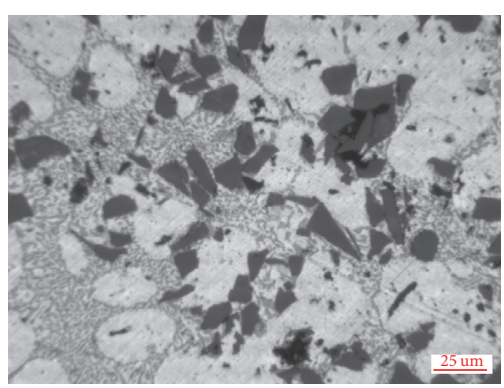

(a)

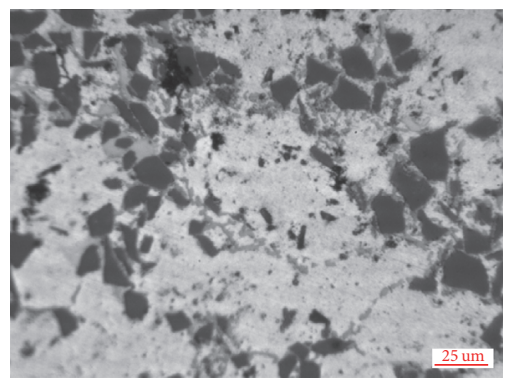

(d)

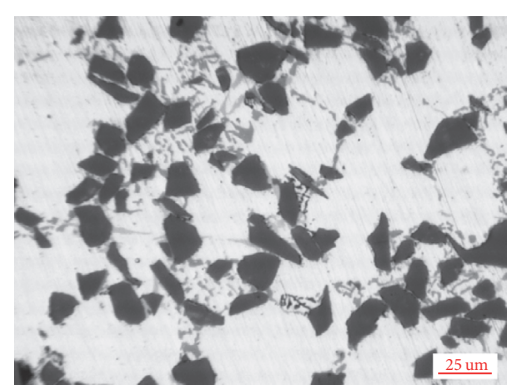

(b)

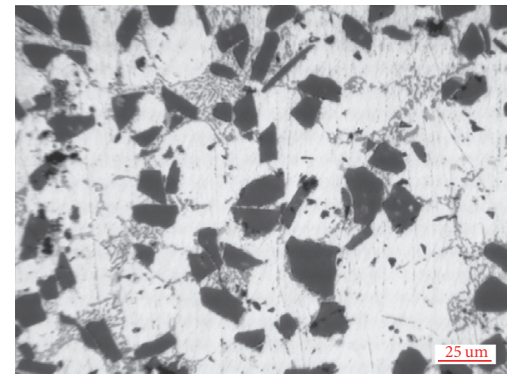

(e)

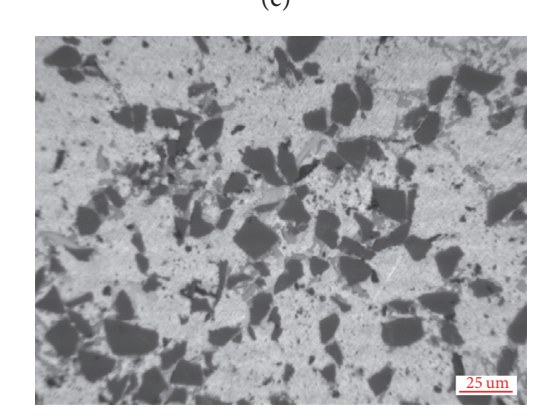

(g)

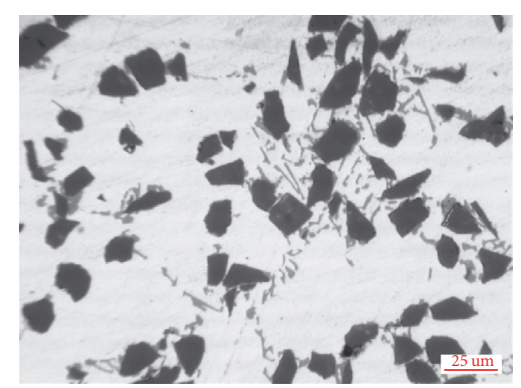

(c)

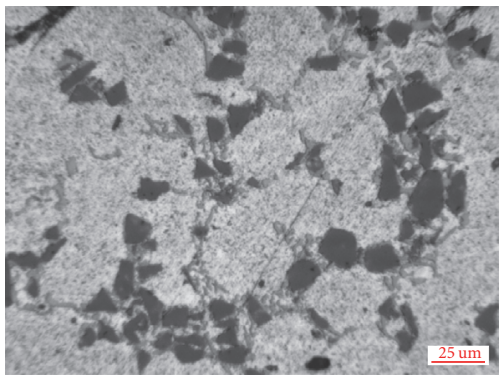

(f)

Figure 4: Microstructure of SiCp/A356 composites fabricated at (a) $620^{\circ} \mathrm{C}, 900 \mathrm{rpm}$, and $20 \mathrm{~min}$; (b) $600^{\circ} \mathrm{C}, 900 \mathrm{rpm}$, and $20 \mathrm{~min}$; (c) $580^{\circ} \mathrm{C}$, $900 \mathrm{rpm}$, and $20 \mathrm{~min}$; (d) $600^{\circ} \mathrm{C}, 600 \mathrm{rpm}$, and $20 \mathrm{~min}$; (e) $600^{\circ} \mathrm{C}, 1200 \mathrm{rpm}$, and $20 \mathrm{~min}$; (f) $600^{\circ} \mathrm{C}, 900 \mathrm{rpm}$, and $10 \mathrm{~min}$; (g) $600^{\circ} \mathrm{C}, 900 \mathrm{rpm}$, and 30 min stirring.

temperature, stirring speed, and volume fraction of $\mathrm{SiC}$ particle.

The different position of volume fraction of $\mathrm{SiC}$ was monitored for simulation and experiment under different stirring temperature, stirring speed, and stirring time. The stirring temperature was 620,600 , and $580^{\circ} \mathrm{C}$, the stirring speed was 600,900 , and $1200 \mathrm{rpm}$, and the stirring time was $30 \% t, 60 \% t$, and $90 \% t$, where $t$ is the time at which $\mathrm{SiC}$ volume fraction reached stable state.

The stirring time of numerical simulation is very difficult to correspond to actual experiment accurately. The numerical simulation results are transient values for different times. In the experimental process, the particle dispersion is changing from the particle clusters to the single particle dispersion gradually and can also be approximated to a steady state process, but there is a great difference for steady state time. Therefore, the dispersion of particles at different stages of the steady state was used to assess the stirring time and corresponding to the actual stirring time.

\section{Results and Discussion}

4.1. Experimental Results and Analysis. Typical optical microstructures of the SiCp/A356 composite samples obtained after polishing are shown in Figure 4. Figure 4 shows the microstructure of composites fabricated at different stirring parameters.

It can be seen from Figures 4(a)-4(c) that the temperature affects the $\mathrm{SiC}$ distribution, and the $\mathrm{SiC}$ particles are uniform at $580^{\circ} \mathrm{C}$ and $600^{\circ} \mathrm{C}, 900 \mathrm{rpm}$, and $20 \mathrm{~min}$ stirring. There are many $\mathrm{SiC}$ agglomerations at $620^{\circ} \mathrm{C}$ stirring, where many particles gather together and the large pores exist. The interface between $\mathrm{SiC}$ and aluminum alloy is weakened because of the $\mathrm{SiC}$ agglomeration [17]. The composite slurry surface is rising with the temperature during the stirring process. Figure 4(a) shows the $\mathrm{SiC}$ particle agglomeration in some local area and there are blank areas with no $\mathrm{SiC}$ particle. The whole performance of the composites is not even.

Figures 4(d) and 4(e) reveal the $\mathrm{SiC}$ distribution at different stirring speed. Compared with Figure 4(b), the SiC 


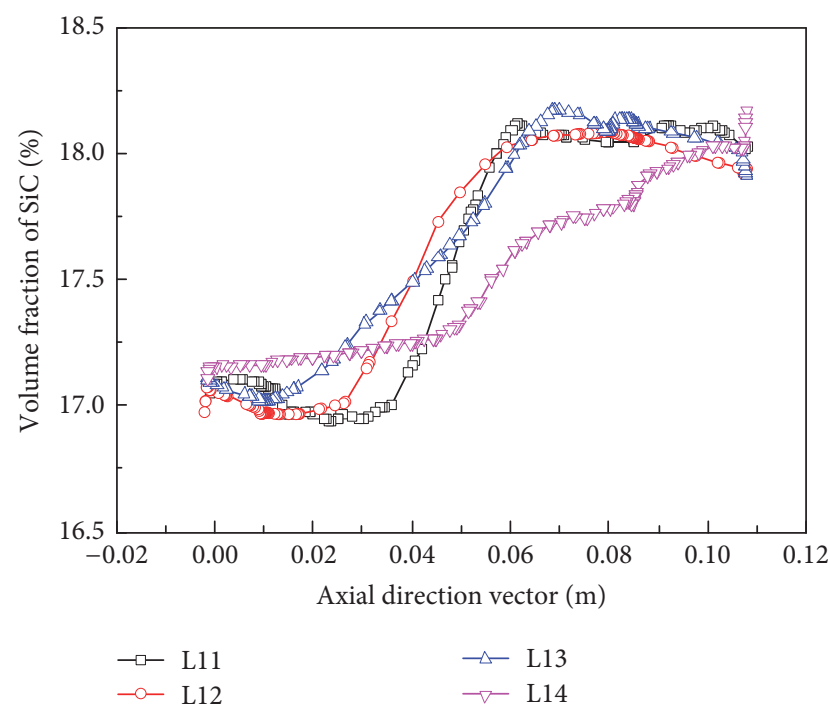

Figure 5: The volume fraction of $\mathrm{SiC}$ changes with the axial direction at different radial position.

particles are more uniform at $900 \mathrm{rpm}$ and $1200 \mathrm{rpm}$ stirring than $600 \mathrm{rpm}$ stirring. But the interface is not clean because the higher stirring speed scratched the stirring rod and crucible. The composite slurry surface is rising with the stirring speed during the stirring process. Figures $4(\mathrm{f})$ and $4(\mathrm{~g})$ show that the $\mathrm{SiC}$ is more uniform at longer stirring time.

\subsection{The Numerical Results and Analysis for Different Radial} Position. Figure 5 is curve of volume fraction of $\mathrm{SiC}$ change with the axial direction; the curves represent lines L11 L14 which located at different radial position of crucible. It is observed that the volume fraction of $\mathrm{SiC}$ at the bottom of crucible is lower than the top of crucible, and the $\mathrm{SiC}$ is poorly dispersed at the position closer to the stirring rod.

Figure 6 indicates the velocity magnitude, tangential velocity, axial velocity, and radial velocity of L11 L14 change with the axial direction at different radial position. The tangential velocity is the main velocity, and the slurry rotated along a circle in the crucible. The velocity at inner diameter and outer diameter is lower than other radial position, where the line speed is larger because of the high speed movement of the liquid. So the dispersion of $\mathrm{SiC}$ is poor at the stirring rod position.

There are fluid exchanges for axial and radial direction at different radial position to achieve mixing and dispersion of $\mathrm{SiC}$ particles. The axial velocity of flow near the stirring rod is transferred from the upward to downward movement along the depth of crucible, and the direction of movement of fluid near the crucible is just the opposite and moves downward to upward. Due to the axial velocity and the effect of the particle gravity, the particle can realize the uniform distribution from the top to the whole depth of the crucible. The radial direction of the fluid along the depth direction moved toward the stirring rod (inner diameter) firstly and then turned toward the crucible wall (outer diameter). The particles can be radially exchanged due to the interaction of the radial fluid.
4.3. The Numerical Results and Analysis for Different Axial Position. Figure 7 is curve of volume fraction of $\mathrm{SiC}$ changes with the radial direction; the curves represent lines L21 L25 which located at different axial position of crucible. It reveals that the distribution of particles in the radial direction is relatively uniform near the bottom and top of the crucible, but the $\mathrm{SiC}$ are not uniformly distributed in the depth direction at the bottom and top of the crucible.

Figure 8 represents the velocity magnitude, tangential velocity, axial velocity, and radial velocity of $\mathrm{L} 21 \sim \mathrm{L} 25$ change with the radial direction at different axial position, and the curves are symmetrical about the axis of the stirring rod. It can be seen that the tangential velocity is the main velocity vector at different depth as well; that is, the melt in the crucible moves toward the circumferential direction with the stirring rod. The aluminum alloy liquid velocity near the outer and inner diameter of the crucible is lower, and the speed of the aluminum alloy liquid is higher where the liquid is in contact with the blade of stirring rod. In addition, the velocity at the bottom and top of the crucible is lower but larger in the adjacent position of the stirring bar.

There are fluid exchanges for axial and radial direction at different axial position to achieve mixing and dispersion of $\mathrm{SiC}$ particles. The axial velocity at the bottom of crucible moves downward firstly and then turns upward. The upward movement speed increases firstly and then decreases. The flow move direction of axial velocity at the top of crucible is opposite to the bottom, but the size of the moving downward speed is also increased and then decreased. The SiC particles could be distributed uniformly at the top and bottom of crucible because of the existence of the axial velocity and its periodic cycle [18]. The radial velocity of flow along direction of the bottom to the top of crucible moves from the inner diameter to the outer diameter of crucible, and the speed of flow is increased firstly and then decreased. The radial velocity of flow at the top crucible is transferred from the inner diameter to outer diameter of crucible, and the speed of flow is also increased firstly and then decreased. The $\mathrm{SiC}$ is distributed uniformly along the radial direction because of the fluid exchanges of inner and outer diameter of crucible.

\subsection{The Simulation Results and Analysis at Different Stirring} Parameters. The simulation results show that the SiC particles distribution in the radial direction is relatively uniform and not uniform in the axial direction. That is, the particle distribution at the bottom and top of crucible is different. In this paper, line L11 data is compared, which is close to the stirring rod located in the inner diameter of crucible, where the particle distribution is poor. The influence of different stirring parameters on $\mathrm{SiC}$ distribution is analyzed by comparing the volume fraction of $\mathrm{SiC}$ along line L11.

The changes of volume fraction of $\mathrm{SiC}$ and velocity magnitude along axis direction and forces, moments, and power at different stirring temperature are shown in Figure 9. The volume fraction of $\mathrm{SiC}$ increases gradually from the bottom to the top of the crucible, and the highest and the lowest value differ $7.8 \%$ at $620^{\circ} \mathrm{C}$ stirring. The results show that the difference of volume fraction of $\mathrm{SiC}$ in axial direction is lower with 


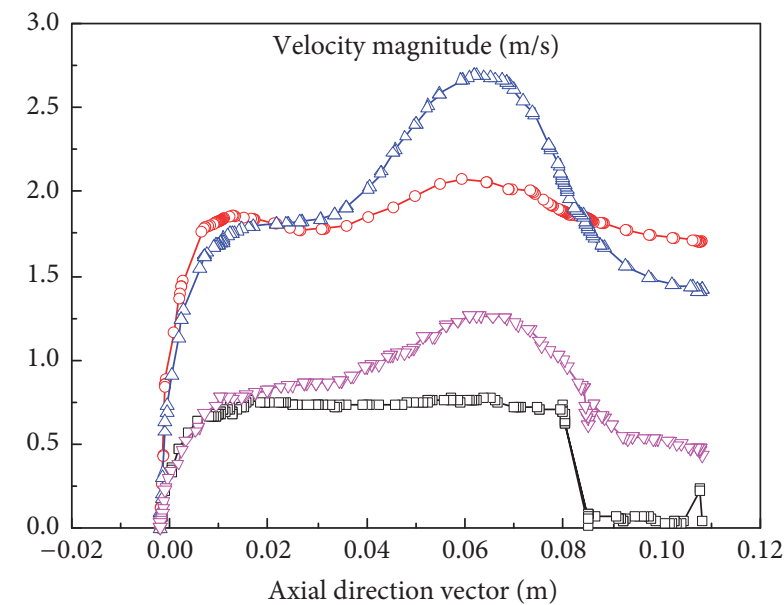

$\rightarrow$ L11

$\multimap$ L12

$\neg$ L13

$\rightarrow$ L14

(a)

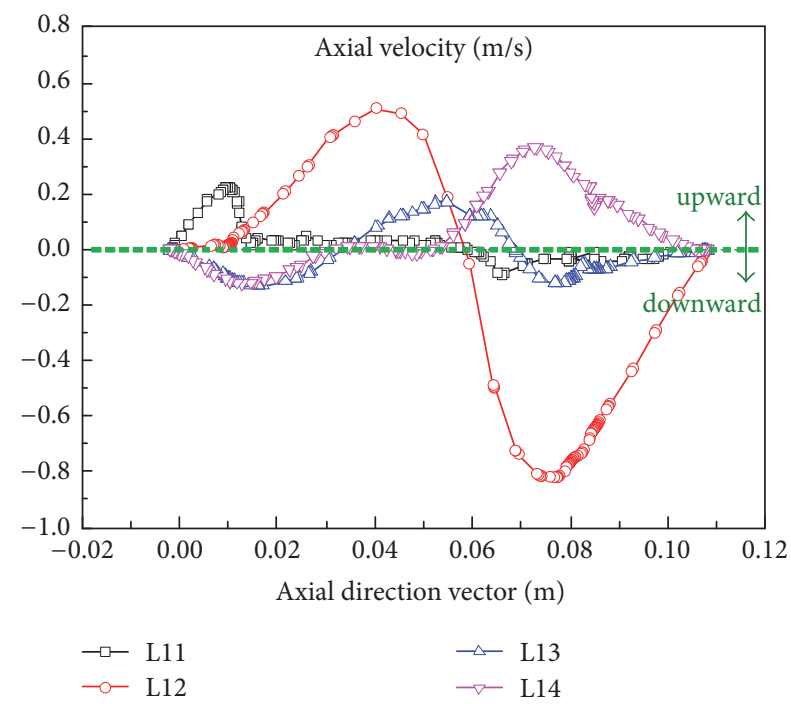

(c)

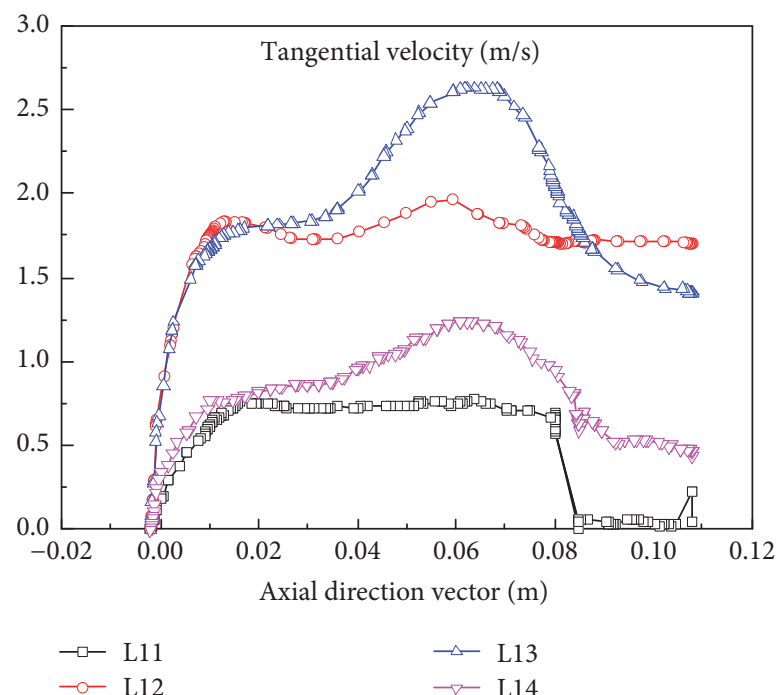

(b)

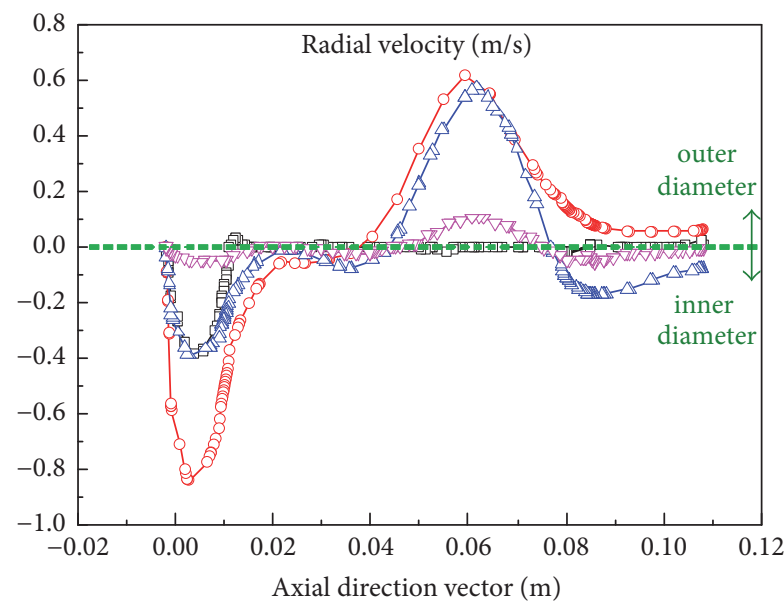

$$
\rightarrow-\mathrm{L} 11 \quad \rightarrow-\mathrm{L} 13
$$

(d)

FIGURE 6: The velocity changes with the axial direction at different radial position: (a) velocity magnitude; (b) tangential velocity; (c) axial velocity; (d) radial velocity.

the decreasing of the stirring temperature, and the minimum difference is $4.3 \%$ at $580^{\circ} \mathrm{C}$ stirring. The velocity of flow is a little different, and speed of flow at bottom and top of crucible reduces with the stirring temperature decreasing, but the stirring shear forces, moments, and power increase.

The solid fraction and viscosity of the semisolid slurry are related to stirring temperature, and the slurry solid volume fraction increases with decreases of stirring temperature [1921 ], and the slurry viscosity and internal resistance increase as well; the fluid speed becomes low at the same stirring speed. The $\mathrm{SiC}$ particles become dispersed more easily because of the friction resistance of $\mathrm{SiC}$ particles increasing and improving the uniformity of distribution. In addition, the resistance of the stirring rod and the stirring force of the particle group also increase with the increases of slurry viscosity, which contribute to the dispersion of the particles. The melt liquid level is easy to rise when the temperature is too high, and the whirlpool is big, which is easy to involve the gas. When the temperature is too low, the viscosity increases, and also the moments and stirring power increase resulting in energy loss.

Figure 10 shows the changes of volume fraction of $\mathrm{SiC}$ and velocity magnitude along axis direction, and forces, moments, and power at different stirring speed, and Figure 11 shows the axial and radial velocity simulated at $600^{\circ} \mathrm{C}, 60 \% t$, and different stirring speed along axis direction. The volume fraction of $\mathrm{SiC}$ increases gradually from bottom to the top of crucible as well, and the maximum difference is $10.4 \%$ at $600 \mathrm{rpm}$ stirring and the minimum difference is $5.8 \%$ at 


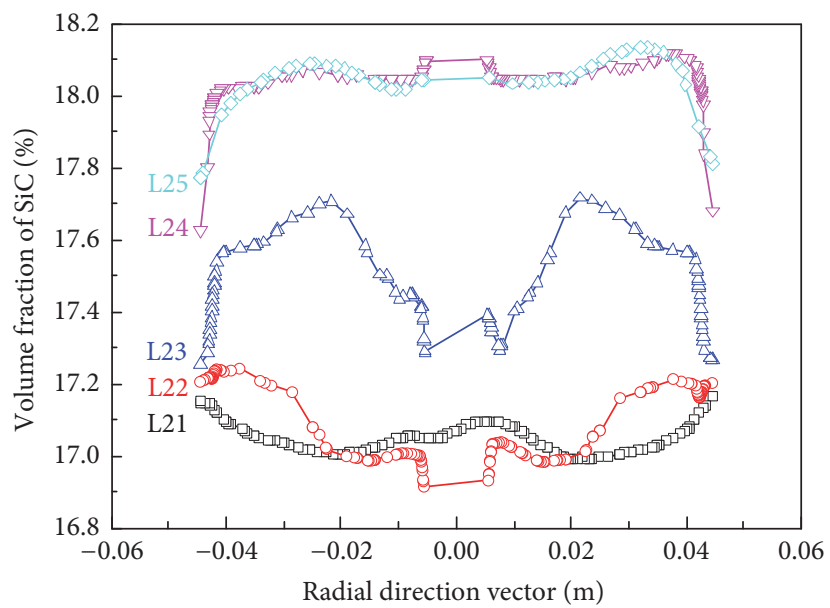

FIGURE 7: The volume fraction of $\mathrm{SiC}$ changes with the radial direction at different axial position.
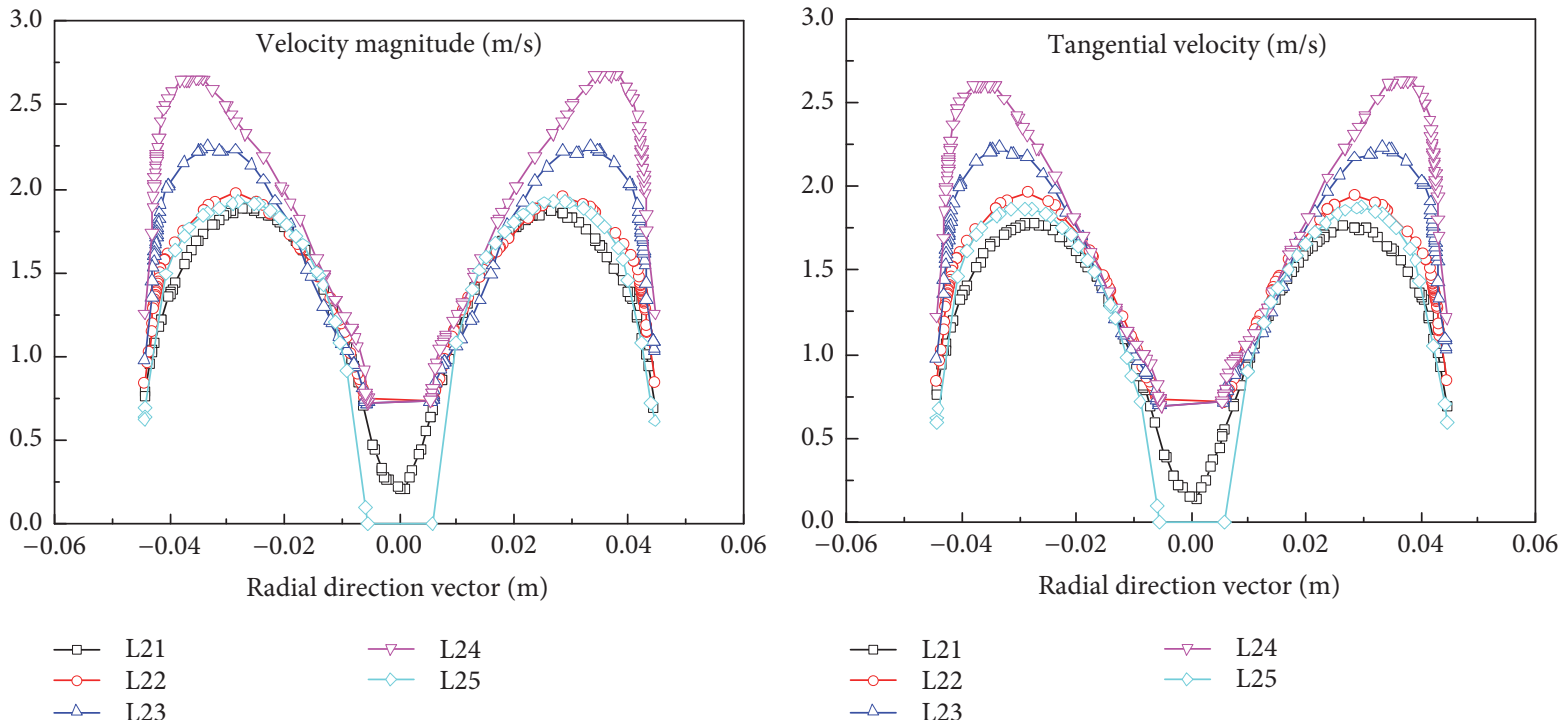

(a)
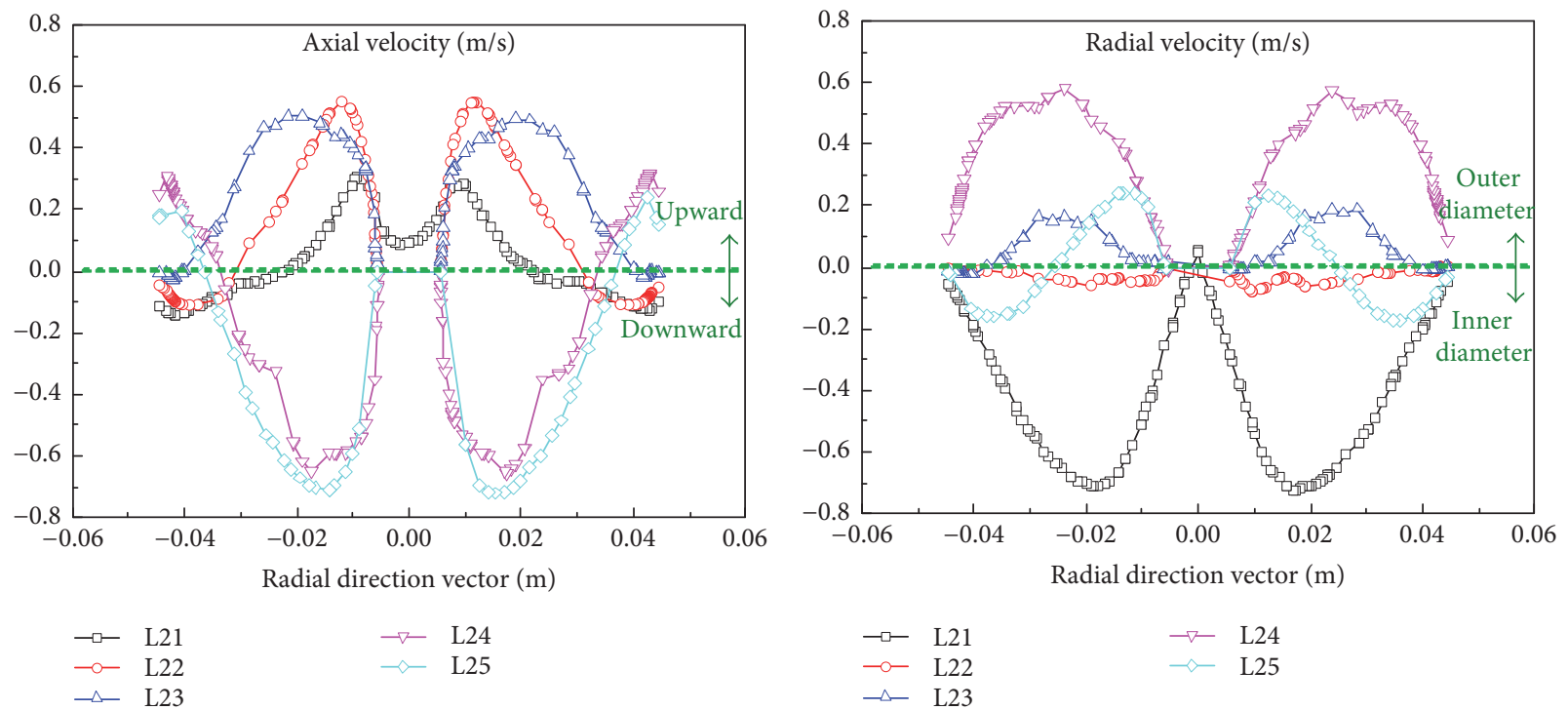

$\begin{array}{ll}\rightarrow- & \mathrm{L} 21 \\ \rightarrow & \mathrm{L} 22 \\ \rightarrow \sim & \mathrm{L} 23\end{array}$

(c)

(d)

FIGURE 8: The velocity changes with the radial direction at different axial position: (a) velocity magnitude; (b) tangential velocity; (c) axial velocity; (d) radial velocity. 


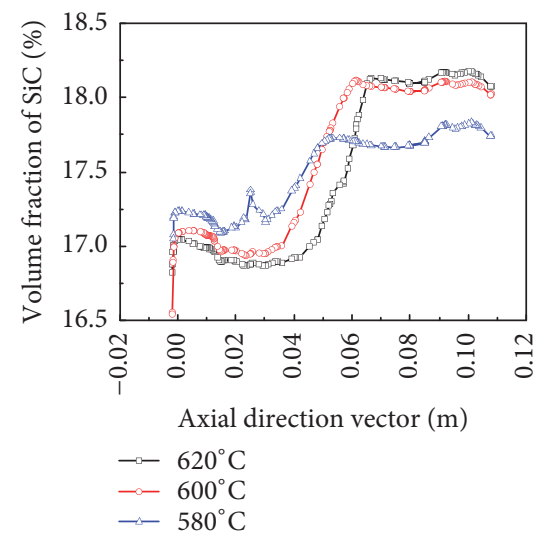

(a)

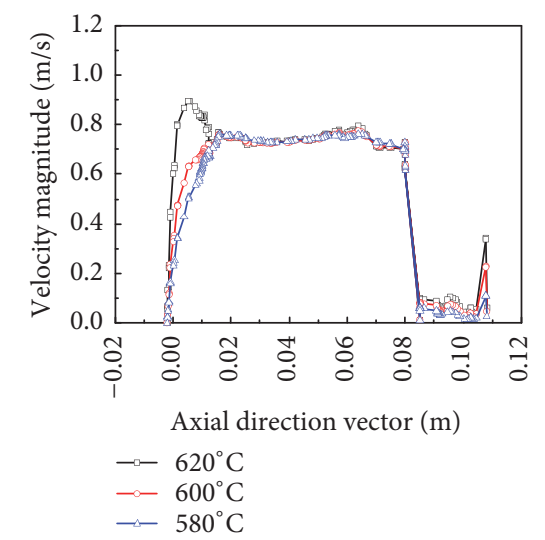

(b)

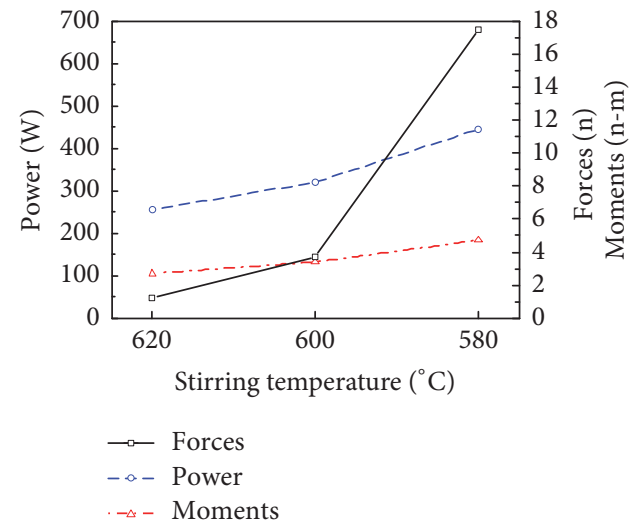

(c)

FiguRE 9: The simulated results of L11 at $900 \mathrm{rpm}, 60 \% t$, and different stirring temperature: (a) volume fraction along axis direction; (b) velocity magnitude along axis direction; (c) forces, moments, and power.

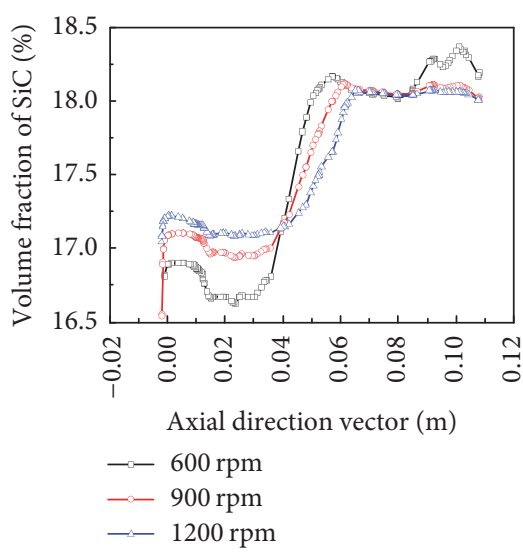

(a)

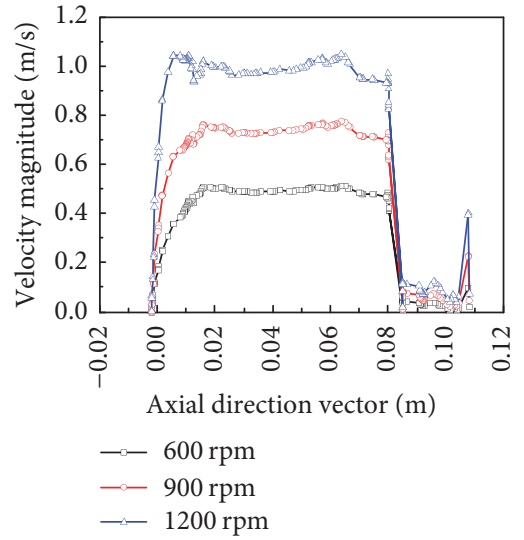

(b)

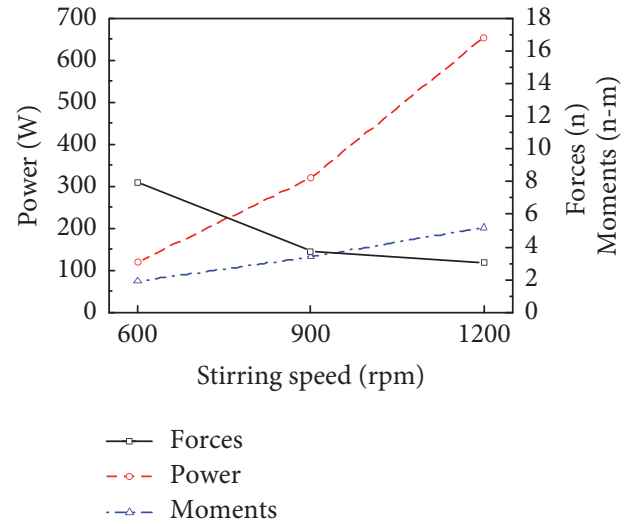

(c)

FIGURE 10: The simulated results of $\mathrm{L} 11$ at $600^{\circ} \mathrm{C}, 60 \% \mathrm{t}$, and different stirring speed: (a) volume fraction along axis direction; (b) velocity magnitude along axis direction; (c) forces, moments, and power.
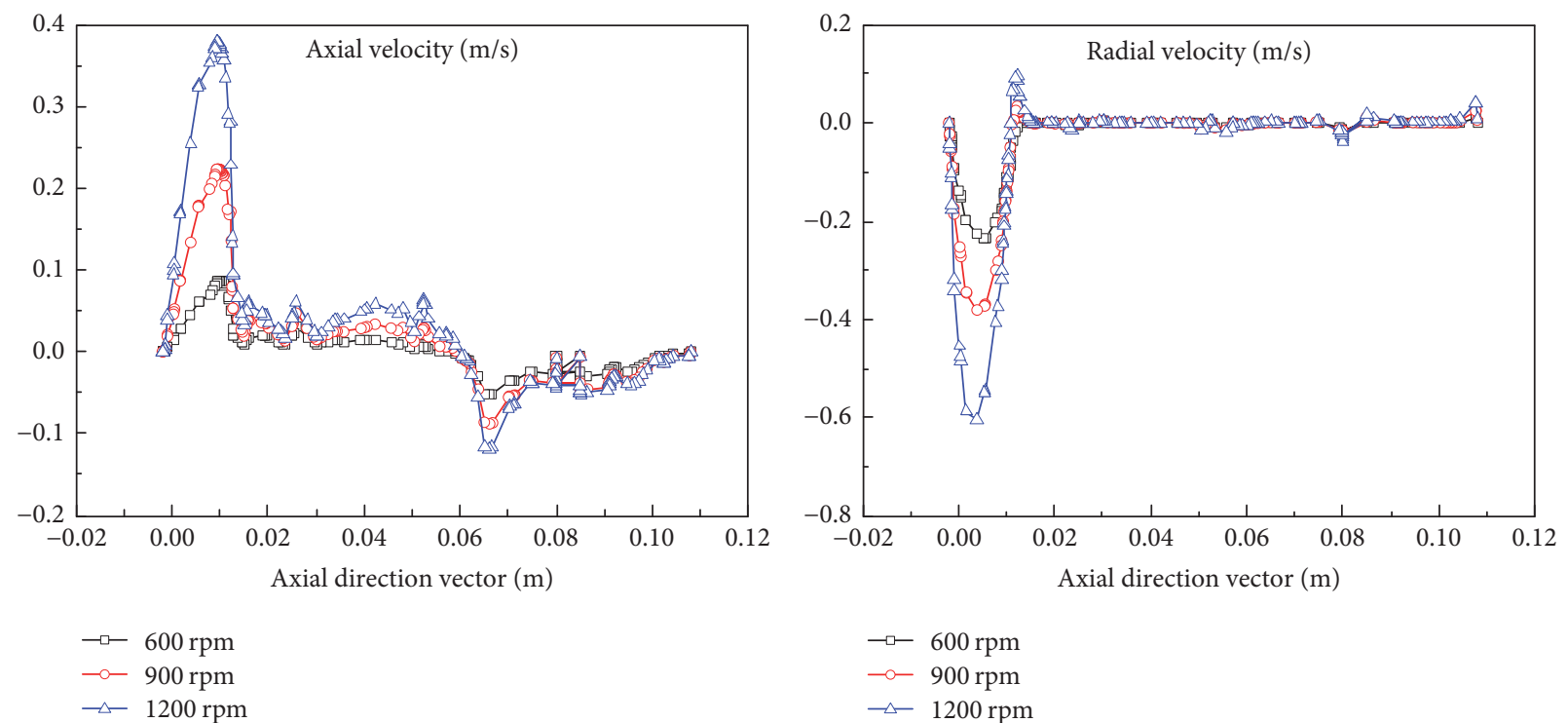

FIGURE 11: The axial and radial velocity simulated at $600^{\circ} \mathrm{C}, 60 \% t$, and different stirring speed along axis direction. 


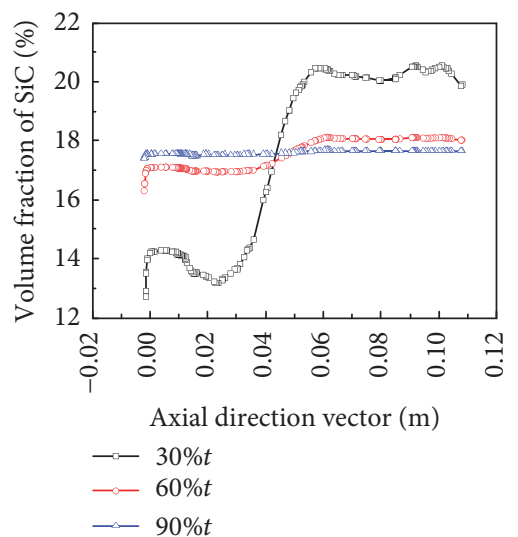

(a)

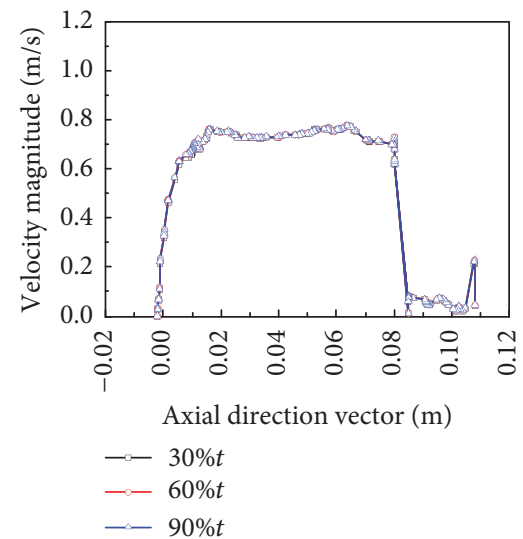

(b)

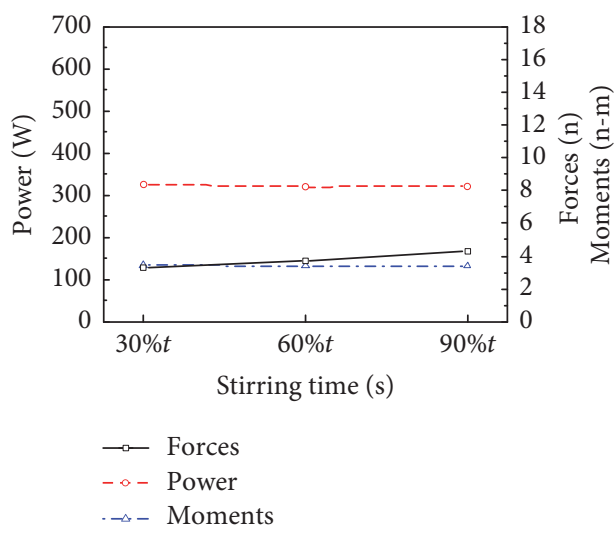

(c)

Figure 12: The simulated results of $\mathrm{L} 11$ at $600^{\circ} \mathrm{C}, 900 \mathrm{rpm}$, and different stirring time: (a) volume fraction along axis direction; (b) velocity magnitude along axis direction; (c) forces, moments, and power.

$1200 \mathrm{rpm}$ stirring. It can be seen clearly that the volume fraction difference of $\mathrm{SiC}$ is little at the $900 \mathrm{rpm}$ and $1200 \mathrm{rpm}$ stirring. The particle distribution is more uniform with the increase of stirring speed. The velocity magnitude, axial velocity, and radial velocity of aluminum liquid increase with acceleration of the stirring speed, which can improve the exchange rate and collision frequency of particles and the stirring rod [21-23]. With the increasing of the stirring speed, the particle dispersion is more uniform, and the moments and power of the stirring rod also increase, but the forces of the stirring rod gradually reduce.

The semisolid aluminum alloy slurry is pseudoplastic fluid [24]. With the increase of stirring speed, slurry viscosity is reducing, and the solid fraction of slurry is also decreasing, resulting in weakening of the shear force and friction on the delegation of the particles, and is detrimental to the dispersion of particles. But with the increase of stirring speed, the velocity of slurry improves, and the displacement of particles per unit of time increases, and the collision frequency of particles and stirring bar increase and are conducive to the dispersion of particles.

It can be seen from Figure 12 that, with the extension of the stirring time, the particle dispersion in the composite is more uniform, but the velocity magnitude, forces, moments, and power have little change. It is found that the dispersion of the particles is improved with the increase of the stirring time through analyzing the numerical simulation and experimental process and results. The longer the stirring time, the more acting the particles with slurry solid component and stirring rod shear forces, which are conducive to the particle dispersion. However, the longer stirring time will also wear the crucible, mixing rod, and other equipment and bring a variety of inclusion and so on, which is not conducive to the performance of the composite.

4.5. Comparison of Simulation and Experimental Results. Figure 13 reveals the particle distribution simulated and measured in the composite stirring at $600^{\circ} \mathrm{C}, 20 \mathrm{~min} / 60 \% t$, and

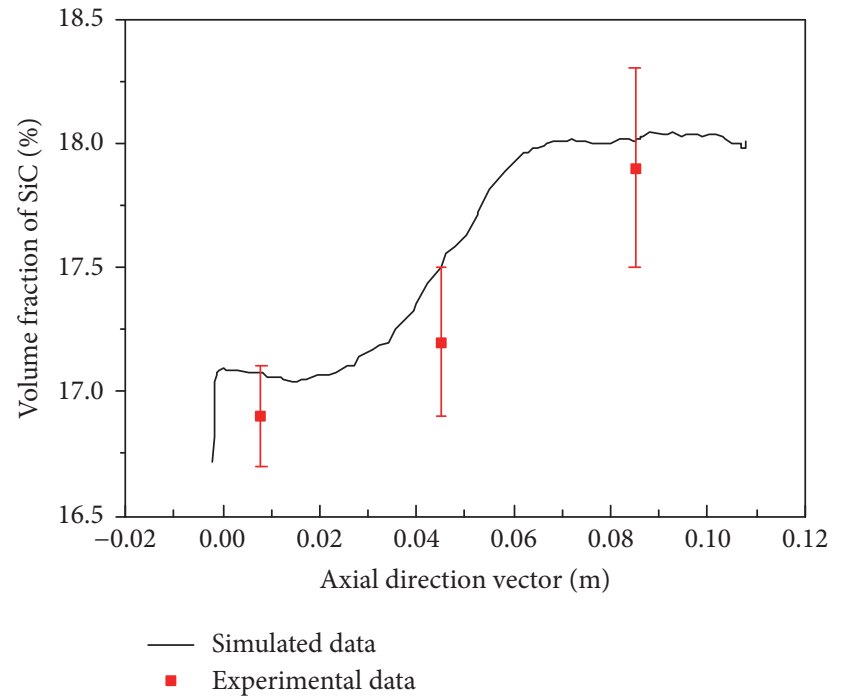

FIGURE 13: Simulated and measured particle distribution in the composite (stirring at $600^{\circ} \mathrm{C}, 20 \mathrm{~min} / 60 \% t$, and $900 \mathrm{rpm}$ ).

$900 \mathrm{rpm}$. The numerical simulation results represent average values at different depth or axial direction of crucible, and experimental results represent the average of the particle content of metallographic sample photos, which were taken from top, middle, and bottom of different position in crucible, and metallographic specimens were made in each location and microstructure pictures were taken 100 times. The Image Pro Plus software was used to account the SiC particle volume fraction in different microstructure. The SiC particle volume fraction in different position of the crucible was measured by taking the average of five metallographic images of microstructure pictures.

It can be seen that the experimental results are basically consistent with the simulation results. The particle content is lower in the bottom of the crucible and higher in the top of the crucible. 
The solidification process also affects the $\mathrm{SiC}$ particle dispersion in the composite due to combined effect of particle settling prior to solidification and particle pushing by the advancing solid-liquid interface during the growth of dendrites $[25,26]$. In this paper, the metal mold was used for casting samples and the solidification rate was the same during different stirring process experiment. So the solidification effect can be neglected for the same casting process in this paper.

It is found that the axial and radial velocity of fluid control the particle movement direction during stirring the semisolid composite, and the shearing force of stirring rod and semisolid slurry is important for the particle distribution, affected by the stirring parameter in this paper. The effect of stirring parameters on the particle distribution is almost the same with Prabua's work [8], which is investigated by experiment, but the influence mechanism of stirring parameters is not clear. Ghosh and Ray [11] also studied the effect of stirring parameters on uniform distribution of particle by scaled-up visualization experiments simulation, but the viscosity was not considered and the findings were not in agreement with the actual results as well. The study of this paper established the method to analyze the stirring parameter on the particle distribution and also clarified how the particle distribution is affected by stirring parameters.

\section{Conclusions}

The vacuum semisolid stirring casting method and CFD numerical simulation technology were used to study the influence of stirring parameters on the dispersion of the particles in SiCp/A356 composite. The influence factors of SiC dispersion were studied by analyzing the slurry velocity, stirring rod shear forces, moments, and power, and the range of stirring parameters for fabricating SiCp/A356 composites was proposed. The main conclusions could be drawn as follows:

(1) Increasing the axial and radial stirring velocity component is helpful to improve the distribution of the $\mathrm{SiC}$ particles in the PMMC.

(2) The greater the shearing force is, the better the dispersion of particles is when the stirring temperature reduced to solid-liquid zone and the near solids.

(3) The higher stirring speed and bigger stirring power are beneficial to the dispersion of particles. However, the viscosity of the slurry decreases with the increase of the semisolid fluid, which is not conducive to the dispersion of particles partly.

(4) The longer the stirring time and the larger the stirring power, the more uniform the particle dispersion.

(5) The particle dispersion of the composites is related to the shear force and the velocity of the fluid.

\section{Conflicts of Interest}

The authors declare that there are no conflicts of interest regarding the publication of this paper.

\section{Acknowledgments}

The authors thank the financial support from the National Key Technology R\&D Program of China (2015BAG12B01-09), the National Natural Science Foundation of China (51271014 and 51371022), and the Fundamental Research Funds for the Beijing Jiaotong University (2015JBM076).

\section{References}

[1] D. J. Lloyd, "Particle reinforced aluminium and magnesium matrix composites," International Materials Reviews, vol. 39, no. 1, pp. 1-23, 1994.

[2] J. Hashim, L. Looney, and M. S. J. Hashmi, "Metal matrix composites: production by the stir casting method," Journal of Materials Processing Technology, vol. 92-93, pp. 1-7, 1999.

[3] J. Hashim, L. Looney, and M. S. J. Hashmi, "Particle distribution in cast metal matrix composites-Part I," Journal of Materials Processing Technology, vol. 123, no. 2, pp. 251-257, 2002.

[4] J. Hashim, L. Looney, and M. S. J. Hashmi, "Particle distribution in cast metal matrix composites-part II," Journal of Materials Processing Technology, vol. 123, no. 2, pp. 258-263, 2002.

[5] S. N. Ahmad, J. Hashim, and M. I. Ghazali, "The effects of porosity on mechanical properties of cast discontinuous reinforced metal-matrix composite," Journal of Composite Materials, vol. 39, no. 5, pp. 451-466, 2005.

[6] P. Z. Zhang and F. G. Li, "Effects of particle clustering on the flow behavior of $\mathrm{SiC}$ particle reinforced $\mathrm{Al}$ metal matrix composites," Rare Metal Materials and Engineering, vol. 39, no. 9, pp. 15251531, 2010.

[7] Y. Su, Q. Ouyang, W. Zhang et al., “Composite structure modeling and mechanical behavior of particle reinforced metal matrix composites," Materials Science and Engineering: A, vol. 597, pp. 359-369, 2014.

[8] S. B. Prabu, L. Karunamoorthy, S. Kathiresan, and B. Mohan, "Influence of stirring speed and stirring time on distribution of particles in cast metal matrix composite," Journal of Materials Processing Technology, vol. 171, no. 2, pp. 268-273, 2006.

[9] N. El-Kaddah and K. E. Chang, "On the dispersion of SiC-Al slurries in rotating flows," Materials Science and Engineering A, vol. 144, no. 1-2, pp. 221-227, 1991.

[10] S. Naher, D. Brabazon, and L. Looney, "Simulation of the stir casting process," Journal of Materials Processing Technology, vol. 143-144, no. 1, pp. 567-571, 2003.

[11] P. K. Ghosh and S. Ray, "A model study on the particle dispersion and fluid-particle interaction in slurry of liquid alloy and ceramic particle," Transactions of the Japan Institute of Metals, vol. 29, no. 6, pp. 502-508, 1988.

[12] K. R. Ravi, V. M. Sreekumar, R. M. Pillai et al., "Optimization of mixing parameters through a water model for metal matrix composites synthesis," Materials and Design, vol. 28, no. 3, pp. 871-881, 2007.

[13] S. Naher, D. Brabazon, and L. Looney, "Computational and experimental analysis of particulate distribution during AlSiC MMC fabrication," Composites Part A: Applied Science and Manufacturing, vol. 38, no. 3, pp. 719-729, 2007.

[14] A. Fluent, Ansys Fluent 12.0 Users Guide, Ansys Inc, 2009.

[15] D. M. Stefanescu, B. K. Dhindaw, S. A. Kacar, and A. Moitra, "Behavior of ceramic particles at the solid-liquid metal interface in metal matrix composites," Metallurgical Transactions A, vol. 19, no. 11, pp. 2847-2855, 1988. 
[16] Y. J. Zhang, W. M. Mao, Z. D. Zhao, and Z. Liu, "Rheological behavior of semi-solid A356 aluminum alloy at steady state," Acta Metallurgica Sinica. Chinese Edition, vol. 42, no. 2, pp. 163166, 2006.

[17] S.-J. Hong, H.-M. Kim, D. Huh, C. Suryanarayana, and B. S. Chun, "Effect of clustering on the mechanical properties of $\mathrm{SiC}$ particulate-reinforced aluminum alloy 2024 metal matrix composites," Materials Science and Engineering A, vol. 347, no. 1-2, pp. 198-204, 2003.

[18] Y. Liang and D. Gao, "Numerical simulation of the three-dimensional flow field in stirred tank with double straight and inclined impeller and its combination," Chinese Journal of Mechanical Engineering, vol. 44, no. 11, pp. 290-297, 2008.

[19] R. Haghayeghi, E. J. Zoqui, A. Halvaee, and M. Emamy, "An investigation on semi-solid $\mathrm{Al}-7 \mathrm{Si}-0.3 \mathrm{Mg}$ alloy produced by mechanical stirring," Journal of Materials Processing Technology, vol. 169, no. 3, pp. 382-387, 2005.

[20] L.-N. Guan, L. Geng, H.-W. Zhang, and L.-J. Huang, "Effects of stirring parameters on microstructure and tensile properties of $(\mathrm{ABOw}+\mathrm{SiCp}) / 6061 \mathrm{Al}$ composites fabricated by semi-solid stirring technique," Transactions of Nonferrous Metals Society of China, vol. 21, no. 31, supplement 2, pp. s274-s279, 2011.

[21] H. Zhang, L. Geng, L. Guan, and L. Huang, "Effects of SiC particle pretreatment and stirring parameters on the microstructure and mechanical properties of $\mathrm{SiCp} / \mathrm{Al}-6.8 \mathrm{Mg}$ composites fabricated by semi-solid stirring technique," Materials Science and Engineering A, vol. 528, no. 1, pp. 513-518, 2010.

[22] Y. Shasha, Z. Peng, D. Yunhui, Z. Jun, and L. Xiaopeng, "Influence of stirring speed on $\mathrm{SiC}$ particles distribution in A356 liquid," China Foundry, vol. 9, no. 2, pp. 154-158, 2012.

[23] S. M. L. Nai and M. Gupta, "Influence of stirring speed on the synthesis of $\mathrm{Al} / \mathrm{SiC}$ based functionally gradient materials," Composite Structures, vol. 57, no. 1-4, pp. 227-233, 2002.

[24] P. A. Joly and R. Mehrabian, "The rheology of a partially solid alloy," Journal of Materials Science, vol. 11, no. 8, pp. 1393-1418, 1976.

[25] A. Çetin and A. Kalkanli, "Effect of solidification rate on spatial distribution of $\mathrm{SiC}$ particles in A356 alloy composites," Journal of Materials Processing Technology, vol. 205, no. 1-3, pp. 1-8, 2008.

[26] A. Çetin and A. Kalkanli, "Numerical simulation of solidification kinetics in A356/SiCp composites for assessment of as-cast particle distribution," Journal of Materials Processing Technology, vol. 209, no. 10, pp. 4795-4801, 2009. 


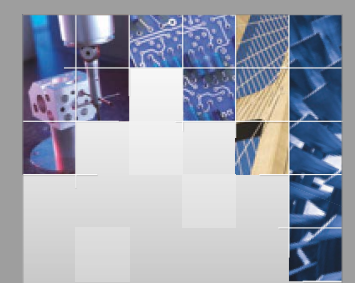

\section{Enfincering}
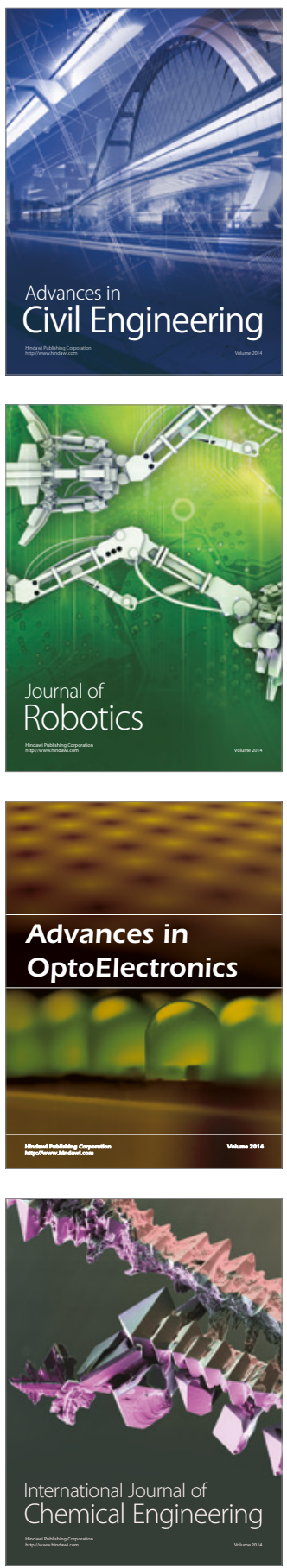

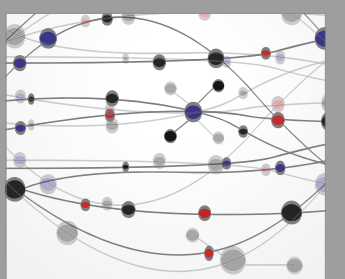

The Scientific World Journal

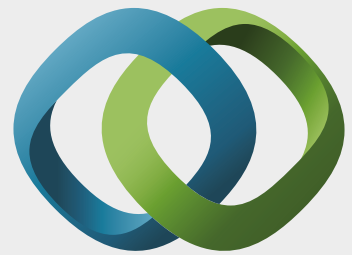

\section{Hindawi}

Submit your manuscripts at

https://www.hindawi.com
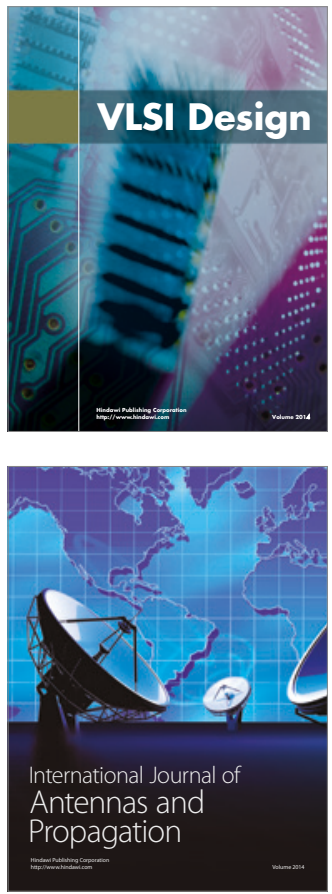

\section{Rotating}

Machinery
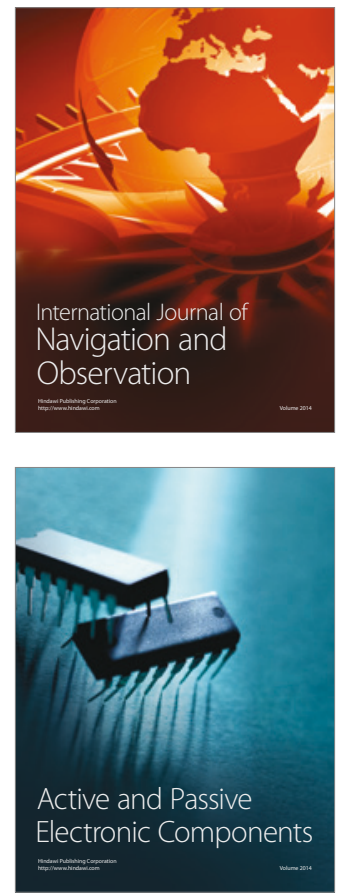
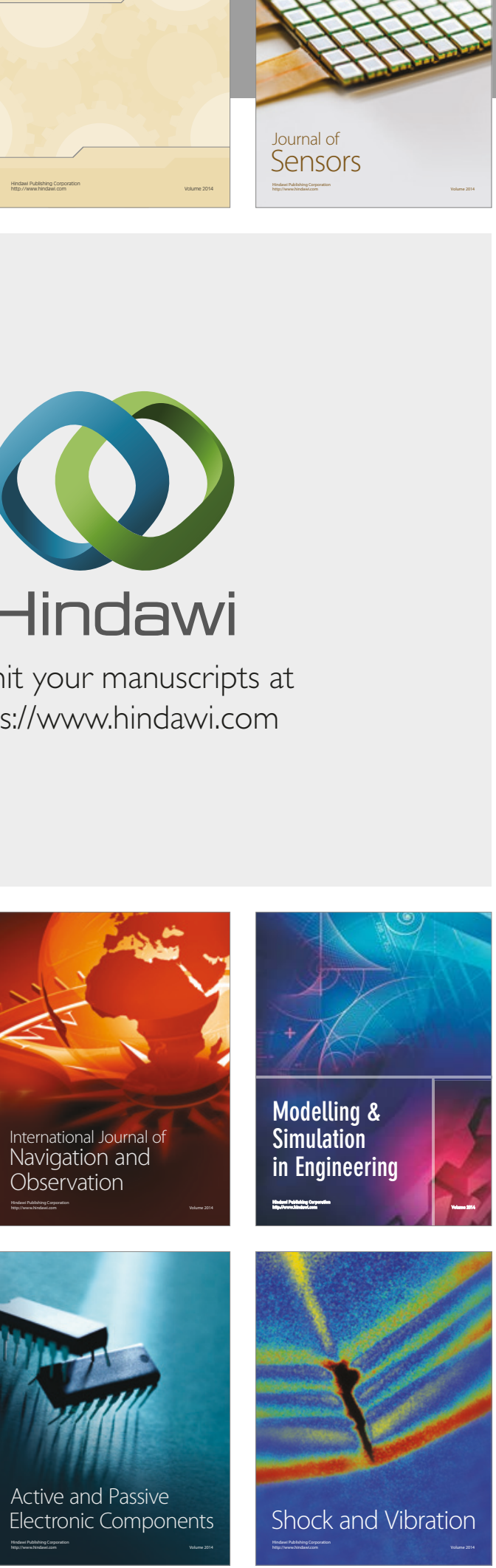
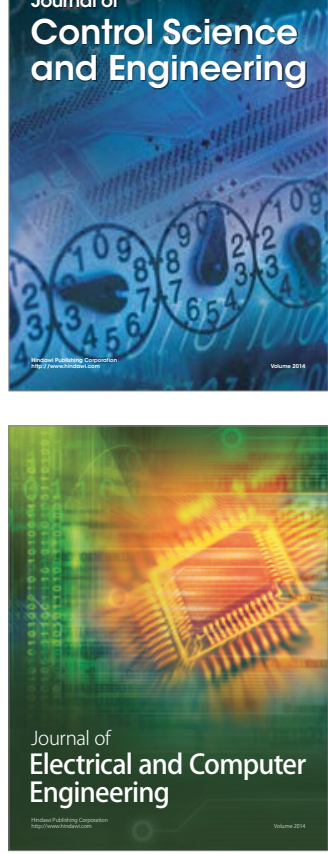

Distributed

Journal of

Control Science

and Engineering
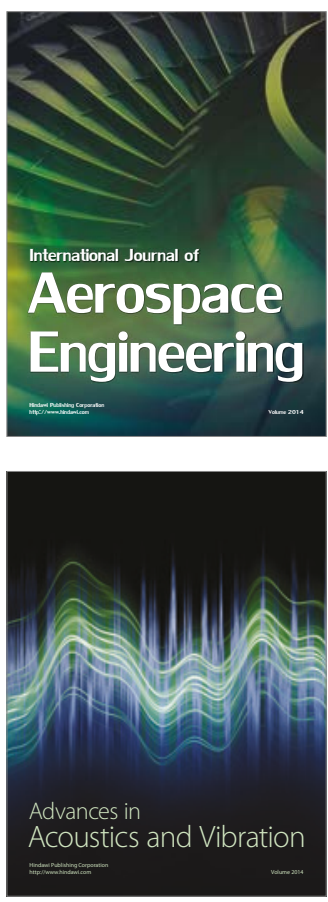

Sensor Networks 